\title{
Analisis Kemampuan Guru Dalam Pembelajaran IPA Menggunakan Alat Peraga (KIT IPA) Di SD Negeri 41 Mataram
}

\author{
M. Zainal Mustamiin \& M. Chairul Anam \\ Institut Keguruan Dan Ilmu Pendidikan Mataram \\ zainalmustamiin@gmail.com, chairulanam@ikipmataram.ac.id
}

\begin{abstract}
Abstrak; tujuan dari penelitian ini untuk (1) Mengetahui kemampuan guru dalam menggunakan alat peraga (KIT IPA) dalam pembelajaran IPA di sekolah dasar dan (2) Memberikan pemahaman kepada guru di sekolah dasar terhadap prosedur dalam menggunakan alat peraga (KIT IPA) dalam pembelajaran IPA. Kemampuan guru dalam pembelajaran IPA menggunakan alat peraga dan KIT IPA perlu keterampilan dan pelatihan khusus. Dalam KIT IPA menyediakan keseluruhan materi ilmu pengetahuan alam (IPA) yang harus dibuktikan dengan melalukan percobaan terhadap materi yang akan diajarkan. Materi-materi yang tersedia dalam KIT IPA di kelas tinggi (4,5, dan 6) diantaranya: (1) alat-alat untuk melakukan percobaan; (2) gambar peraga untuk peragaan; dan (3) daftar nama-nama benda dan bahan-bahan yang diperlukan untuk melakukan percobaan. Jenis penelitian ini adalah deskriptif dengan menggunakan kusioner sebagai instrument pengumpulan data.
\end{abstract}

\section{Kata Kunci : Kemampuan Guru, Alat Peraga, IPA}

\section{Pendahuluan}

Satuan Pendidikan sebagai salah satu sektor sumber pembangunan dan penyerapan sumberdaya manusia yang dikelola oleh tenaga yang professional dalam menghasilkan peserta didik yang berkualitas. Kemampuan dalam mengelola sebuah satuan pendidikan harus didukung dengan manajerial yang professional dan tentunya dukungan sarana dan prasana yang memadai. Dalam pembelajaran IPA, ketersedian media pembelajaran, alat peraga, dan KIT IPA di sekolah sudah dapat dikategorikan terpenuhi. Penggunaan alat-alat peraga IPA, media pembelajaran, serta KIT IPA dibutuhkan kemampuan guru dalam mengoperasikannya.

Kemampuan guru dalam pembelajaran IPA menggunakan alat peraga dan KIT IPA perlu keterampilan dan pelatihan khusus. Dalam KIT IPA menyediakan keseluruhan materi ilmu pengetahuan alam (IPA) yang harus dibuktikan dengan melalukan percobaan terhadap materi yang akan diajarkan. Materi-materi yang tersedia dalam KIT IPA di kelas tinggi $(4,5$, dan 6) diantaranya: (1) alat-alat untuk melakukan percobaan; (2) gambar peraga untuk peragaan; dan (3) daftar nama-nama benda dan bahan-bahan yang diperlukan untuk melakukan percobaan. Pembelajaran IPA untuk sekolah dasar peserta didik dapat Jurnal IImiah Mandala Education diarahkan pada pengembangan cara kerja, sikap (afektif), dan cara berpikir dalam memecahkan masalah sehari-hari. Sikap yang ditunjukkan peserta didik dalam hal tersebut adalah sikap ilmiah.

Keterampilan dan kemampuan guru dalam membelajarkan IPA kepada peserta didik dengan menggunakan alat peraga (KIT IPA) perlu dilakukan analisis. Kreativitas dan inovasi khusus dalam pembelajaran IPA akan menyebabkan proses pembelajaran menarik dan aktif. Hal tersebut diperjelas oleh Lewis et.al (2014: 27) yang menyatakan bahwa

activity provides a quick and practical means of transforming science lessons to be more engaging for students. Through this activity teachers can redesign any science lesson by focusing on each of the five core components of a scientific classroom discourse community: (a) scientific inquiry, (b) oral discourse, (c) written discourse, (d) academic language development, and (e) learning principles

Maksud dari pernyataan di atas bahwa aktivitas pembelajaran yang menyediakan cara cepat dan praktis untuk menginovasi pembelajaran IPA menjadi lebih menarik bagi peserta didik dengan menggunakan alat peraga (KIT IPA). Dengan menggunakan alat peraga dapat memusatkan perhatian pada kelas ilmiah diantaranya; (1) penyelidikan 
ilmiah; (2) wacana lisan; (3) tertulis wacana; (4) pengembangan bahan akademik; dan (5) prinsip belajar.

Berdasarkan hasil wawancara yang dilakukan di SD Negeri 41 Mataram mengenai kemampuan guru-guru di kelas tinggi (4,5, dan 6) dalam menggunakan KIT IPA dalam proses pembelajaran IPA masih belum terlaksana dengan baik. Ketersediaan alat peraga (KIT IPA) di sekolah tersebut tidak dimanfaat dengan baik oleh guru dalam menunjang pembelajaran IPA yang berkualitas, kontekstual, dan ilmiah. Dengan demikian, peneliti perlu melakukan penelitian mengenai analisis kemampuan guru dalam pembelajaran IPA menggunakan alat peraga (KIT IPA) di SD Negeri 41 Mataram.

Tujauan dari penelian ini untuk MENGETAHUI kemampuan guru dalam menggunakan alat peraga (KIT IPA) dalam pembelajaran IPA di sekolah dasar,dan Memberikan pemahaman kepada guru di sekolah dasar terhadap prosedur dalam menggunakan alat peraga (KIT IPA) dalam pembelajaran IPA.

Manfaat yang dapat diperoleh dari penelitian ini yaitu: 1). Menjadi rujukan bagi guru di sekolah dasar untuk meningkatkan kemampuan dalam menggunakan alat peraga (KIT IPA) pada pembelajaran IPA. 2) Memberikan pemahaman kepada guru mengenai prosedur dalam komponenkomponen dalam alat peraga (KIT IPA).3. Meningkatkan kemampuan guru dalam memanfaatkan alat peraga dalam keseluruhan mata pelajaran di sekolah dasar.

Ilmu pengetahuan alam (IPA) merupakan salah satu mata pelajaran yang mempelajari tentang penyelidikan dan pengukuran sebagai bagian dari pengamatan. Pembelajaran IPA di sekolah dasar lebih difokuskan pada sikap ilmiah yang dilakukan oleh peserta didik. Hal tersebut sesuai dengan komponen salah satu komponen IPA diantaranya: IPA sebagai produk ilmiah, IPA sebagai proses ilmiah, dan IPA sebagai sikap ilmiah. Bundu (2008: 12) menyatakan bahwa sikap ilmiah menyangkut proses atau cara kerja untuk memperoleh hasil (produk), inilah yang kemudian dikenal sebagai proses ilmiah. Melalui proses-proses ilmiah akan didapatkan temuan-temuan ilmiah. Keterampilan proses
IPA adalah keterampilan yang dilakukan oleh para ilmuwan.

Lebih lanjut, Trianto ( 2007:99) mengungkapkan bahwa dalam kehidupan sehari- hari proses pembelajaran IPA menekankan pada pemberian pengalaman langsung untuk mengembangkan kompetensi kompetensi agar menjelajahi dan memahami alam sekitar secara ilmiah serta diarahkan untuk inquiri dan berbuat sehingga dapat membantu peserta didik untuk memperoleh pemahamn yang lebih mendalam tentang alam sekitar.

berdasarkan beberapa pendapat di atas dapat disimpulkan bahwa IPA merupakan salah satu kumpulan ilmu pengetahuan yang mempelajari alam semesta, baik ilmu yang mempelajari alam semesta yang bernyawa ataupun yang tak bernyawa dengan jalan mengamati berbagai jenis dan peranggai lingkungan alam asli serta lingkungan buatan.

Tujuan Pembelajaran IPA di SD menurut BSNP (2006:37) bertujuan agar peserta didik memiliki kemampuan sebagai berikut: 1) Memperoleh keyakinan terhadap kebesaran tuhan yang maha esa berdasarkan keberadaan, keindahan, keteraturan alam ciptaannya,2) Menegembangkan pengetahuan dan pemahaman konsep-konsep IPA yang bermanfaat dan dapat diterapkan dalam kehidupan sehari-hari,3) Mengembangkan rasa ingin tahu, sikap positif dan kesadaran tentang adanya hubungan yang saling mempengaruhi antara IPA, lingkungan, teknologi masyarakat,3) serta Mengembangkan keterampilan proses untuk menyelidiki alam sekitar, memcahkan masalah dan membuat keputusan, 4) Meningkatkan kesadaran untuk berperan serta dalam memelihara, menjaga, dan melestarikan alam,5) Meningkatkan kesadaran untuk menghargai alam dan segala keteraturannya sebagai salah satu ciptaan tuhan,6) Memperoleh bekal pengetahuan, konsep dan keterampilan IPA sebagai dasar untuk melanjutkan Pendidikan ke SMP/MTS.

Menurut Mulyasa (2006: 110-111) pembelajaran IPA sebaiknya dilaksanakan secara inkuiri dan berbuat, untuk memperoleh pemahaman yang mendalam tentang alam dan 11 menumbuhkan kemampuan berpikir, bekerja dan bersikap ilmiah. 
Berdasarkan uraian di atas pembelajaran IPA di SD/MI lebih menekankan pada pemberian pengalaman langsung sesuai kenyataan dilingkungan melalui kegiatan inkuiri untuk mengembangkan keterampilan proses dan sikap ilmiah.

Dalam pengajaran, KIT IPA mempunyai kedudukan yang penting, yaitu membantu pengembangan konsep- konsep ilmu pengetahuan alam, media dapat memberikan dasar- dasar yang konkrit untuk berpikir sehingga dapat menghindari pemahaman yang verbalisme,memberikan pengalaman yang nyata dapat menumbukan kegiatan sendiri,serta menimbulkan pemahaman yang teratur dan berkesinambungan kemudian diperjelas lagi oleh Teemu Paavolainen (117) yang menyatakan bahwa

props could be considered prototypical of theatrical objects--Veltrusky's continuum, allowing a degree of creativity to our fuzzying up or extending their conceptual boundaries-but then again, I wouldn't expect even most theatre people to have a clear prototype for the overall category of props, given its level of abstraction. Just as we cannot interact with or purchase or draw or visualize a "general piece of furniture" (one that isn't a chair, a table, or a bed, for instance), we cannot do those things to a prop in general. On what is considered a cognitively basic level-one at which category members look much more alike and call for similar interactions (contrast chairs with furniture or beanbags)-we would have to think of particular props and the particular motions that make them props

maksud peryataan di atas Alat peraga dapat dianggap sebagai benda-benda utama, yang memungkinkan tingkat kreativitas untuk membuat kita memikat atau memperluas batas konseptual, tapi sekali lagi, namun alat peraga mampu memberikan gambaran /me nerjemahkan seluruh abstraksi sehinga memberikan kemampuan kognitif awal.

Berdasarkan uraian tersebut di atas, maka dapat disimpulkan bahwa penggunaan alat peraga dalam proses belajar mengajar dapat membantu siswa untuk mempermudah memahami suatu konsep atau prinsip yang Jurnal Ilmiah Mandala Education diajarkan, membantu guru dalam proses belajar mengajar, dan membuat siswa lebih aktif belajar.

\section{Metode Penelitian}

Tahap-tahap penelitian ini dibagi menjadi 3 tahap yaitu

1. Menentukan masalah penelitian, dalam tahap ini peneliti mengadakan studi pendahuluan.

2. Pengumpulan data, pada tahap ini peneliti mulai dengan menentukan sumber data, yaitu referensi yang berkaitan dengan permasalahan yang diperoleh di SDN 41 mataram. Pada tahap ini diakhiri dengan pengumpulan data dengan menggunakan metode observasi, wawancara dan dokumentasi.

3. Analisis dan penyajian data yaitu menganalisis data menarik kesimpulan

Penelitian ini telah dilaksanakan di SDN 41 Mataram dengan waktu penelitian selama 4 bulan.dengan menggunakan pendekatan deskriptif, yaitu penelitian yang menggambarkan suatu obyek yang berkenaan dengan masalah yang diteliti tanpa mempersoalkan hubungan antar variabel penelitian.

Rancangan Penelitian

Adapun rancangan dari penelitian ini sebagai berikut.

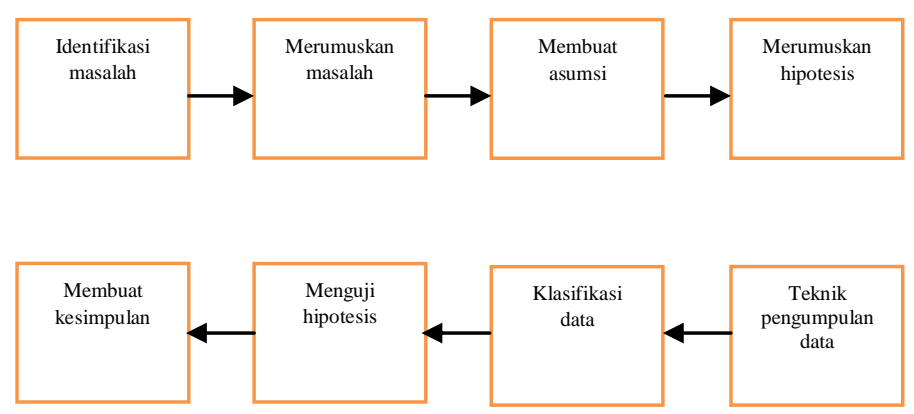

Pengumpulan Data dilakukan dengan cara

a. Valid tidaknya suatu penelitian tergantung pada jenis pengumpulan data yang digunakan untuk pemilihan metode yang tepat dan sesuai dengan jenis dari sumber data. Teknik pengumpulan data adalah upaya untuk mengamati variabel yang diteliti melalui metode tertentu. Adapun teknik pengumpulan datanya dilakukan dengan menggunakan Metode sebagai berikut : 1. Metode observasi Observasi diartikan sebagai pengamatan atau 
pencatatan dengan sistematik fenomenafenomena yang diselidiki. Metode ini diterapkan dalam rangka mengamati proses penerapan KIT IPA menggunakan metode

b. Metode Interview/ wawancara Yaitu sebuah dialog yang dilakukan oleh pewawancara untuk memperoleh informasi dari yang diwawancarai. Metode ini diterapkan dalam upaya memperoleh informasi dari yang diwawancarai tentang implementasi penggunaan KIT IPA .

c. Yaitu metode yang digunakan untuk mencari data mengenai hal-hal yang berupa benda-benda tertulis, buku-buku, majalah, dokumentasi, peraturan, catatan harian.Metode ini penulis gunakan untuk memperoleh data dari SDN 41 Mataram.

Analisis Data

Menganalisis data merupakan kegiatan inti yang terpenting dan paling menentukan dalam penelitian. Analisis data adalah proses mengatur urutan data. Mengorganisasikannya dalam suatu pola, kategori dan satuan uraian dasar. Analisis data ini dilakukan dalam suatu proses yang pelaksanaannya mulai dilakukan sejak pengumpulan data dilakukan dan dikerjakan secara intensif yaitu sesudah meninggalkan lapangan

\section{Deskripsi Data Hasil Penelitian}

Data penelitian ini disajikan secara deskriptif yang berisi kemampuan guru dalam menggunakan alat peraga IPA dalam proses pembelajaran di kelas pada mata IPA. Data tersebut diperoleh dari penelitian eksperimen dengan menggunakan alat peraga IPA baik pada kelas eksperimen dan kelas kontrol.

Data hasil belajar dengan menggunakan alat peraga IPA diperoleh dari hasil pelaksanaan pretest dan posttest sebelum kegiatan eksperimen dilakukan. Jumlah yang mengikuti pretes berjumlah 54 siswa dengan rincian yaitu 32 siswa kelas eksperimen dan 22 siswa kelas kontrol. Pengambilan data dimaksudkan untuk mengetahui keefektifan penggunaan alat peraga IPA dalam proses pembelajaran IPA di kelas.

1. Deskripsi data hasil pretest kelas eksperimen dan kelas kontrol.

Pengambilan data pretest dilaksanakan pada tanggal 3 Agustus 2018 sebelum pelaksanaan tindakan kepada peserta didik. Deskripsi data hasil pretest kelas eksperimen dan kelas kontrol tersebut disajikan dalam bentuk data terhadap kemampuan guru dalam menggunakan alat peraga IPA dalam proses pembelajaran di kelas.

a. Deskripsi data hasil pretest kelas ekxperimen

Deskripsi data hasil pretest kelas eksperimen ini menjelaskan tentang kemampuan guru dalam menggunakan alat peraga IPA dalam proses pembelajaran di kelas. Deskripsi data pretest ini menyajikan tentang skor rata-rata (mean), median, standar deviasi, skor minimum, dan skor maksimum.

Berikut data hasil pretes pada kelas eksperimen dapat dilihat pada tabel di bawah ini.

Tabel 1. Data hasil pretest kemampuan guru dalam menggunakan alat peraga IPA pada kelas eksperimen.

\begin{tabular}{|l|l|c|}
\hline No & \multicolumn{1}{|c|}{ Perolehan } & $\begin{array}{c}\text { Pretest kelas } \\
\text { eksperimen }\end{array}$ \\
\hline 1 & Maximum Valic Missing & 32 \\
\hline 2 & Mean & 33.6 \\
\hline 3 & Median & 34.00 \\
\hline 4 & Mode & 33.0 \\
\hline 5 & Standar deviasi & 4.39 \\
\hline 6 & Skor minimum & 41.0 \\
\hline 7 & Sum & 1075. \\
\hline
\end{tabular}

Berdasarkan tabel di atas dapat diketahui bahwa nilai rata-rata yang diperoleh sebesar 33.59, dengan median sebesar 34, standar deviasi sebesar 4.38, dan skor terendah sebesar 26 dan skor tertinggi sebesar 41.

Berdasarkan hasil analisis statistik deskriptif dengan menggunakan SPSS 16 for Windows, skor rata-rata yang diperoleh guru dalam menggunakan alat peraga IPA dalam proses pembelajaran di kelas pada kelas eksperimen sebesar 33.59 dengan standar deviasi 4.38 , dan skor tertinggi mencapai 41 dan skor terendah sebesar 26.

Deskripsi Data Posttest Kelas Eksperimen

Deskripsi data hasil posttest kelas eksperimen ini menjelaskan tentang hasil kemampuan guru dalam menggunakan alat peraga IPA pada proses pembelajaran di 
kelas. Deskripsi data posttest ini disajikan dalam bentuk nilai rata-rata (mean), median, standar deviasi, skor minimum, dan skor maksimum.

Berikut disajikan rangkuman data hasil posttest pada kelas eksperimen pada tabel di bawah ini. Tabel 2. Deskripsi data hasil posttest kelas eksperimen.

\begin{tabular}{|l|l|c|}
\hline No & \multicolumn{1}{|c|}{ Perolehan } & $\begin{array}{c}\text { Posttest kelas } \\
\text { Eksperimen }\end{array}$ \\
\hline 1 & $\begin{array}{l}\text { Maximum Valic } \\
\text { Missing }\end{array}$ & 32 \\
\hline 2 & Mean & 38.03 \\
\hline 3 & Median & 40.0 \\
\hline 4 & Mode & 30.0 \\
\hline 5 & Standar deviasi & 48.4 \\
\hline 6 & Skor minimum & 30 \\
\hline 7 & Nilai maksimum & 44 \\
\hline 8 & Sum & 1217.0 \\
\hline
\end{tabular}

Berdasarkan tabel di atas dapat diketahui bahwa diperoleh nilai rata-rata sebesar 38.03, median sebesar 40, standar deviasi sebesar 4.85, skor terendah sebesar 30, dan skor tertinggi sebesar 44 .

\section{Deskripsi data posttest kelas kontrol}

Deskripsi data hasil posttest kelas kontrol ini menjelaskan tentang hasil kemampuan guru dalam menggunakan alat peraga IPA pada proses pembelajaran di kelas. Deskripsi data posttest ini disajikan dalam bentuk nilai rata-rata (mean), median, standar deviasi, skor minimum, dan skor maksimum.

Berikut disajikan rangkuman data hasil posttest pada kelas kontrol pada tabel di bawah ini. Tabel 3 Deskripsi data hasil posttest kelas kontrol.

\begin{tabular}{|l|l|c|}
\hline No & \multicolumn{1}{|c|}{ Perolehan } & $\begin{array}{c}\text { Posttest kelas } \\
\text { kontrol }\end{array}$ \\
\hline 1 & $\begin{array}{l}\text { Maximum Valic } \\
\text { Missing }\end{array}$ & 22 \\
\hline 2 & Mean & 34.3 \\
\hline 3 & Median & 34.5 \\
\hline 4 & Mode & 31.0 \\
\hline 5 & Standar deviasi & 4.02 \\
\hline 6 & Skor minimum & 28.0 \\
\hline 7 & Nilai maksimum & 41.0 \\
\hline 7 & Sum & 755.0 \\
\hline
\end{tabular}

Berdasarkan tabel di atas dapat diketahui bahwa diperoleh nilai rata-rata sebesar 34.3, median sebesar 34.5, standar deviasi sebesar 4.02, skor terendah sebesar 28, dan skor tertinggi sebesar 41.

\section{Kesimpulan}

Berdasarkan hasil penelitian dan pembahasan yang telah diuraikan pada bab sebelumnya, maka dapat diperoleh kesimpulan sebagai berikut:

1. Kemampuan guru dalam menggunakan alat peraga IPA dalam proses pembelajaran di kelas pada kelas eksperimen. Kategori skor tinggi dengan perincian tersebut merepresentasikan bahwa kemampuan guru dalam menggunakan alat peraga IPA dalam proses pembelajaran tergolong tinggi dengan peroleh nilai rata-rata sebesar 38.03, median sebesar 40, standar deviasi sebesar 4.85, skor terendah sebesar 30, dan skor tertinggi sebesar 44 .

2. Kemampuan guru dalam menggunakan alat peraga IPA dalam proses pembelajaran di kelas pada kelas eksperimen. Kategori skor tinggi dengan perincian tersebut merepresentasikan bahwa kemampuan guru dalam menggunakan alat peraga IPA dalam proses pembelajaran tergolong tinggi dengan perolehan diperoleh nilai rata-rata sebesar 34.3, median sebesar 34.5, standar deviasi sebesar 4.02, skor terendah sebesar 28, dan skor tertinggi sebesar 41 .

\section{DAFTAR PUSTAKA}

Bundu, P. (2006). Penilaian keterampilan proses dan sikap ilmiah dalam pembelajaran sains SD. Jakarta: Departemen Pendidikan Nasional Lewis, et.al (2014). A professional learning community activity for science teacher: How to incorporate discourse-rich instructional strategies into science lessons. Journal Summer, Vol. 23, No. $1, \operatorname{Pg} 2$.

Pasley, et.al. (2004). Looking inside the classroom: Science teaching in the United States. Jounal Spring, Vol. 13, No. 1, pg4

Trianto. (2007). Mendesain model pembelajaran inovatif-progressif. Jakarta: Kencana Prenanda Media. Teemu Paavolainen ( 2010). From props to affordances: an ecological approach to theatrical objects. Journal Gale Arts, Vol. 18.No. 8249. Pg. 18 